\title{
Efficacy of Point-of-Care Testing (POCT) in Reducing Total Waiting Time at Warfarin Clinic of a District Hospital: A Cohort Study
}

\author{
Ganesh Kasinathan ${ }^{*}$, Shakirin Pairan1, Sirajudeen Rowther ${ }^{1}$, Sharifah Sulaiman'2, \\ Siti A. Basimin ${ }^{3}$, Norazema Samsuni ${ }^{4}$, Vidhubala Balasegar ${ }^{4}$ \\ ${ }^{1}$ Department of Medicine, Segamat Hospital, Johor, Malaysia \\ ${ }^{2}$ Venepuncture and Specialist Clinic Services, Segamat Hospital, Johor, Malaysia \\ ${ }^{3}$ Department of Pharmacy, Segamat Hospital, Johor, Malaysia \\ ${ }^{4}$ Department of Pathology, Segamat Hospital, Johor, Malaysia \\ Email: "concorde842000@yahoo.com
}

Received 4 February 2016; accepted 19 February 2016; published 24 February 2016

Copyright (C) 2016 by authors and OALib.

This work is licensed under the Creative Commons Attribution International License (CC BY). http://creativecommons.org/licenses/by/4.0/

(c) (i) Open Access

\section{Abstract}

Introduction: This study was chosen due to long waiting time at various stages before doctors/ pharmacists saw patients at warfarin clinic. Objectives: The objectives are to identify stages contributing to waiting time and to assess efficacy of point-of-care testing (POCT) in reducing waiting time at warfarin clinic. Methodology: This study was conducted in two phases. Phase 1 (pre intervention) consisted of 171 patients attending warfarin clinic over three weeks (06/04/2015-27/ 04/2015). Phase 2 (post intervention) consisted of 148 patients $(26 / 10 / 2014-09 / 11 / 2015)$. Patients with rejected INR samples and multiple clinics on the same day were excluded. Data were analysed using SPSS 17. Results/Discussion: 171 patients were recruited in phase 1. 67.3\% (115) Malays, $22.8 \%$ (39) Chinese, $9.4 \%$ (16) Indians and $0.6 \%$ (1) others. The mean age was 62.8 years. $54.4 \%$ (93) were males compared to $45.6 \%$ (78) females. Significant waiting time was from arrival of patient at venepuncture to blood taking which was 38.3 minutes $\pm 19.3, p<0.001$. Blood taken at venepuncture to sample arrive at laboratory was 29.1 minutes $\pm 13.9, \mathrm{p}<0.001$. The mean time to see pharmacist was 44.2 minutes \pm 24.5 . The mean time to see doctor for both stable/deranged INR was $58.7 \pm 27.1, p<0.001$. Average 36.7 minutes \pm 23.8 was spent at doctor's room, $p<0.001$. Time spent from pharmacist receiving prescription to warfarin dispensed was $16.3 \pm 7.2$, $p<$ 0.001. Percentage of patients with total waiting time in the post intervention study (arrival at venepuncture to dispensing of warfarin) less than 180 minutes is $96.7 \%$ (compared to $21.6 \%$ in the pre intervention group). The set standard is $\mathbf{8 0 \%}$. Causes contributing towards excessive waiting time were delay in transporting samples to laboratory, delay in blood taking at venepuncture, delay in sending results to warfarin clinic and poor delegation of task between doctors/pharmacists. The signifycant improvement in waiting time was attributed to the point-of-care testing (POCT) device which avoided the need to send samples to the laboratory. Conclusion: The point-of-care

${ }^{*}$ Corresponding author.

How to cite this paper: Kasinathan, G., Pairan, S., Rowther, S., Sulaiman, S., Basimin, S.A., Samsuni, N. and Balasegar, V. (2016) Efficacy of Point-of-Care Testing (POCT) in Reducing Total Waiting Time at Warfarin Clinic of a District Hospital: A Cohort Study. Open Access Library Journal, 3: e2428. http://dx.doi.org/10.4236/oalib.1102428 
testing (POCT) system provides a reliable and accurate alternative in monitoring patients on oral anticoagulation therapy.

\title{
Keywords
}

\author{
Warfarin, Doctors, Testing, Hospital, Waiting Time
}

Subject Areas: Internal Medicine

\section{Introduction}

This study topic was chosen due to long waiting time at various stages before doctors or pharmacists see patients at the warfarin clinic. The warfarin clinic is one of the clinics with a high patient load at the medical outpatient department of Segamat Hospital. It is conducted on every Monday by several medical officers and assisted by one or two pharmacists. There are various steps involved before patients are prescribed the correct dose of warfarin to achieve the target international normalised ratio (INR). Common cases seen at the warfarin clinic include atrial fibrillation, prosthetic heart valves and venous thromboembolism. The waiting time for patients is one of the important factors that should be considered in the management and organization of the heath care system [1]. Nowadays, customer care in all the organizations particularly the health care organizations has been advanced [1]. Prompt treatment in hospitals means to minimize the time for getting a health service with an emphasis on favourable treatment [2]. The main problem related to the waiting time is obtained from three main factors: people (consumers), organizations providing health services (suppliers), and environment [3]. Health care quality emphasizes on patient's satisfaction in general and this involves several processes. One of these processes in the health care organizations is the process of the appropriate management of waiting time [4]. This study topic was mainly chosen due to its seriousness of the problem. Long waiting time can lead to increased dissatisfaction among patients especially in the elderly with multiple co-morbidities. Data can be collected and measured using prepared recorded waiting time sheets. It is appropriate as it relates to patient's quality of care. Besides that, it is remediable as waiting time can be reduced at various stages with implementation of corrective measures. The point-of-care testing (POCT) system provides an accurate and reliable alternative in reducing waiting time for patients on oral anticoagulation therapy. The point-of-care testing coagulometer measures the prothrombin time and INR (the globally recommended unit for measuring thromboplastin time) in people on oral anticoagulation (vitamin K antagonist) therapy. Besides that, point-of-care testing (POCT) within primary care settings eliminates delays in waiting for the result of prothrombin time measurement to be processed by the hospital laboratory, and the subsequent delay in adjustment of anti-coagulation dosing. It also avoids the need to attend hospital anticoagulation clinics [5]. Patients' self-tests can either adjust their medication according to a pre-determined dose-INR schedule (self-management) or they can call a clinic to be told the appropriate dose adjustment (self-monitoring) [6]. Several trials of self-monitoring of oral anticoagulant therapy suggest this may be equal to or better than standard monitoring [6]. The process of care at our conventional warfarin clinic is as illustrated in Figure 1.

\section{Methodology}

\subsection{Pre Intervention Study (Phase 1)}

This qualitative cohort study was conducted over a period of three weeks from the $6^{\text {th }}$ of April 2015 to the $27^{\text {th }}$ of April 2015 at the warfarin clinic of Segamat Hospital, Johor, Malaysia. The number of participants recruited was 171. The sampling population of this study includes all consecutive eligible patients visiting the warfarin clinic of Segamat Hospital during the study period. Participants with multiple different clinics on the same day, rejected INR (International Normalised Ratio) blood samples, defaulters and patients with many co-morbidities were excluded from this study. The distribution of patients in all the months was equal in the previous year. To ensure accuracy of data, the waiting time was measured on the basis of minutes and seconds by the researchers. Data was collected using prepared recorded waiting time data collection sheets. The data were analysed using 

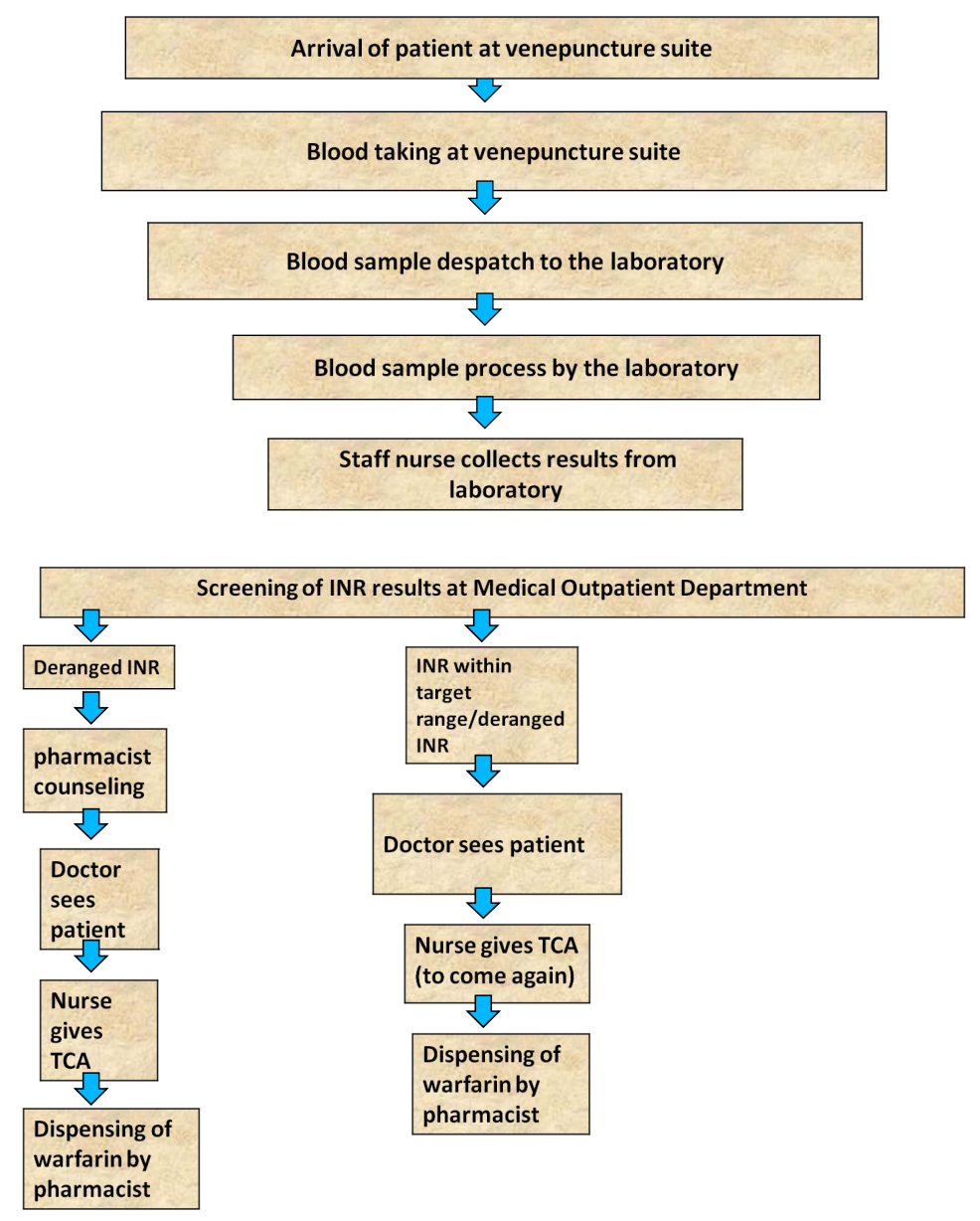

Figure 1. Process of care at conventional warfarin clinic.

IBM SPSS version 17. The data with quantitative variables were expressed by mean and standard deviation while the qualitative variables were estimated by frequency and percentage. Statistical analysis was estimated using Multiple Linear Regression which was expressed through p values. P value less than 0.05 is considered as statistically significant.

\subsection{Post Intervention Study (Phase 2)-Using Point-of-Care Testing (POCT)}

This second phase of the study was conducted 6 months after the pre intervention study. This study was conducted over three weeks from the $26^{\text {th }}$ of October 2015 to the $9^{\text {th }}$ of November 2015. The sample size for this study was 148 patients. The inclusion and exclusion criteria were the same as for the pre intervention study. The CoaguChek coagulometer was used by drawing a precise amount of blood from the patient's finger pulp using a lancet. The sample volume required was very small $(15-30 \mu \mathrm{L})$. The results were typically available in less than 5 minutes. The INR readings were then documented on the data collection sheet. Once the INR reading was known using this coagulometer, the patient then sees the doctor for consultation.

\section{Results}

Socio-Demographic characteristics of participants in Phases 1 (pre intervention) and 2 (post intervention) are as shown in Table 1 and Table 2.

\section{Discussion}

In this qualitative cohort study, they were many stages as described above which contributed to long waiting 
Table 1. Socio-demographic factors among study participants.

\begin{tabular}{ccc}
\hline Socio-demographic factors & Phase $\mathbf{1} \%$ (n) & Phase $\mathbf{2} \%$ (n) \\
\hline Ethnic Malay & $67.3(115)$ & $66.2(98)$ \\
Ethnic Chinese & $22.8(39)$ & $29.0(43)$ \\
Ethnic Indian & $9.4(16)$ & $4.8(7)$ \\
Others & $0.6(1)$ & $0.0(0)$ \\
Gender Male & $54.4(93)$ & $47.3(70)$ \\
Gender Female & $45.6(78)$ & $52.7(78)$ \\
Mean Age & 62.8 years old & 64.2 years old \\
Married & $86.5(148)$ & $76.4(113)$ \\
Single & $4.1(7)$ & $14.3(21)$ \\
Divorced & $4.7(8)$ & $3.3(5)$ \\
Widowed & $4.7(8)$ & $6.0(9)$ \\
Professional & $14.6(25)$ & $12.2(18)$ \\
Non Professional & $55.6(95)$ & $54.1(80)$ \\
Homemaker & $5.8(10)$ & $8.8(13)$ \\
Unemployed & $4.2(7)$ & $10.8(16)$ \\
Retired & $19.8(34)$ & $14.2(21)$ \\
\hline
\end{tabular}

Table 2. Stages (in chronology) contributing to total waiting time (AtoG) at warfarin clinic. P value $<0.05$ is considered significant.

\begin{tabular}{|c|c|c|c|}
\hline Stages at warfarin clinic & $\begin{array}{l}\text { Pre intervention (Phase 1) } \\
\text { Mean time in mins (SD) }\end{array}$ & $\begin{array}{l}\text { Post intervention (Phase 2) } \\
\text { Mean time in mins (SD) }\end{array}$ & $P$ value \\
\hline $\begin{array}{l}\text { A. Patient reaches venepuncture (to) blood } \\
\text { sample taken } \\
\text { (standard: }<\mathbf{3 0} \text { mins) }\end{array}$ & $38.3(19.3)$ & $26.2(11.4)$ & $<0.001$ \\
\hline $\begin{array}{l}\text { B. Blood taken (to) blood arrive at } \\
\text { laboratory } \\
\text { (standard: }<\mathbf{1 5} \text { mins) }\end{array}$ & 29.1 (13.9) & $\begin{array}{l}\text { Not applicable } \\
\text { (POCT device used) }\end{array}$ & \\
\hline $\begin{array}{l}\text { C. Blood sample arrive at laboratory (to) } \\
\text { INR results ready } \\
\text { (standard: }<\mathbf{6 0} \text { mins) }\end{array}$ & $27.8(10.3)$ & $\begin{array}{c}\text { Not applicable (POCT device } \\
\text { used) }\end{array}$ & \\
\hline \multicolumn{4}{|l|}{ D. INR result ready (to) patient seen by: } \\
\hline $\begin{array}{l}\text { 1. Pharmacist } \\
\text { (standard: }<\mathbf{3 0} \text { mins) }\end{array}$ & $44.2(24.5)$ & $14.0(6.1)$ & 0.30 \\
\hline $\begin{array}{c}\text { 2. Doctor } \\
\text { (standard: }<\mathbf{3 0} \text { mins) }\end{array}$ & $58.7(25.2)$ & $35.1(22.1)$ & $<0.001$ \\
\hline $\begin{array}{l}\text { E. Patient seen by pharmacist (to) pt seen by } \\
\text { doctor }\end{array}$ & $24.0(9.6)$ & $26.8(10.4)$ & 0.29 \\
\hline $\begin{array}{l}\text { F. Patient seen by doctor (to) pharmacist } \\
\text { receive prescription }\end{array}$ & 36.7 (23.8) & 31.9 (20.9) & $<0.001$ \\
\hline $\begin{array}{c}\text { G. Pharmacist receive prescription (to) } \\
\text { warfarin dispensed } \\
\text { (standard: }<\mathbf{3 0} \text { mins) }\end{array}$ & $16.3(7.2)$ & $15.7(6.8)$ & $<0.001$ \\
\hline $\begin{array}{l}\text { Total Waiting Time } \\
\text { Less than } 180 \text { mins }\end{array}$ & $21.6 \%$ & $96.7 \%$ & \\
\hline
\end{tabular}

(Standard: based on Ministry of Health, Malaysia). 
time namely involving the division of venepuncture and the warfarin clinic. Causes contributing towards excessive waiting time in the phase 1 study were mainly delay in transport of blood samples from venepuncture to the laboratory. This could be attributable to lack of porters or staff to facilitate delivery of samples to the laboratory. There was no coordinator available to facilitate transport of blood specimens. The porter or staff nurse will collect the blood specimens in batches before sending them to the laboratory.

Another level significantly affected was time patient spent at the venepuncture for blood taking. This could be due to no designated warfarin lane for blood taking for warfarin patients. Patients from all specialist clinics were designated for blood taking on the same day as for warfarin patients thus increasing the workload for venepuncture staff.

Delay in collecting results from the laboratory to warfarin clinic also significantly contributed to the long waiting time. This was due to shortage of staff at the warfarin clinic and the staff had to juggle with the multiple tasksof attending to patients at the clinic and also collection of results from the laboratory.

Poor delegation of task between doctors and pharmacists also contributed to this problem. Pharmacists sat at different consultation rooms contributing to repeated counseling for patients by doctors.

The length of time between INR test dates varies, the maximum recommended length of time allowed between INR tests is 12 weeks [7]. The secondary care anticoagulation clinic may decide to transfer in situations where the patient's INR is not stable, but where it would be beneficial for the patient to be monitored in primary care [8]. In the district of Segamat, primary care facilities for anticoagulation monitoring are limited. There is no government clinic which provides anticoagulation services and this increases the workload on the hospital service.

Using patient self testing such as the CoaguChek offers a reliable alternative to laboratory determination of INR and is acceptable to the majority of suitably trained patients who previously attended a specialist anticoagulation clinic [9]. Point-of-care testing (POCT) coagulometers for measuring coagulation status in people receiving long-term vitamin $\mathrm{K}$ antagonist therapy allow both self-testing and self-management, defined as follows:

- Self-testing: point-of-care test carried out by the patient with test results managed by their health-care provider [e.g. general practitioner (GP), nurse, specialised clinic].

- Self-management: point-of-care test carried out by trained patient, followed by interpretation of test result and adjustment of dosage of anticoagulant according to a predefined protocol [10].

The point-of-care testing coagulometer measures the prothrombin time and INR (the globally recommended unit for measuring thromboplastin time) in people on oral anticoagulation (vitamin K antagonist) therapy [10]. The POC devices use electrochemical methods or function by drawing a precise amount of blood into a microchannel and detect clot formation when the blood movement decreases below a predetermined rate [5]. The sample volume required is very small $(15-30 \mu \mathrm{L})$ with few user dependent steps. The results are typically available in less than 5 minutes [11].

A recent systematic review on the precision and accuracy of POC coagulometers reviewed the evidence for CoaguChek XS, INRatio, and ProTime/ProTime 3 [12]. Across 14 studies on the accuracy of CoaguChek, the correlation coefficient varied from 0.81 to 0.95 [5]. Three studies on the accuracy of INRatio reported correlation coefficients from 0.92 to 0.95 and four studies on the accuracy of ProTime/ProTime 3 reported correlation coefficients from 0.72 to 0.90 [5]. The review concluded that accuracy of POC coagulometers was comparable to laboratory measures and generally adequate for clinical use [5]. Evidence on patient self-monitoring of oral anticoagulation therapy shows improvement in anticoagulant control and reduced risk of thrombosis compared to clinic-based care [5]. Several subsequent randomised controlled trials have shown that anticoagulation selfmanagement was at least as good as or in some cases better than conventional management with INR values showing smaller variance and fewer major thromboembolic and bleeding complications in older people [13].

The most common testing frequency is weekly, but lower frequency of testing can be justified based on the patient's condition [5].

This may obliviate the need for patients to queue at venepuncture for blood taking.

The National Institute for Health and Care Excellence (NICE) clinical guideline on atrial fibrillationrecommends that self-monitoring of INR should be considered for people with atrial fibrillation receiving long-term anticoagulation, if they prefer this form of testing and if the following criteria are met such as [14]:

- the patient (or a designated carer) is both physically and cognitively able to perform the self-monitoring test

- an adequate supportive educational programme is in place to train participants and/or carers;

- the patient's ability to self-manage is regularly reviewed; 
- the equipment for self-monitoring is regularly checked via a quality control programme.

Besides the above, having more pharmacist personnel in the warfarin clinic may increase patient satisfaction and quality of care. Transition of patients from a pharmacist managed anticoagulation clinic back to a physician managed anticoagulation care after stabilization of warfarin therapy was associated with significant decrease in INR control and decreased patient satisfaction [9].

Many major healthcare institutions utilize the Lean and Six Sigma approach with significant results. Most of the problems relating to long waiting time could be resolved by adhering to this model [15].

\section{Conclusion}

The point-of-care testing (POCT) system provides a reliable and accurate alternative in monitoring patients on oral anticoagulation therapy. There is a potential benefit in reducing the length of clinic time. INR self-monitoring also allows an enhanced stability within a target range, and also helps to prevent serious complications.

\section{Conflict of Interest}

The authors declare that there is no conflict of interest regarding the publication of this paper.

\section{Ethical Approval}

Ethical approval was obtained prior to commencement of this study.

\section{References}

[1] Mohebbifar, R., Hasanpoor, E., et al. (2014) Outpatient Waiting Time in Health Services and Teaching Hospitals: A Case Study in Iran. Global Journal of Health Sciences, 6, No. 1.

[2] Dansky, K.H. and Miles, J. (2007) Patient Satisfaction with Ambulatory Healthcare Services: Waiting Time and Filling Time. Hospital and Health Services Administration, 42, 165

[3] Boudreaux, E.D., D’Autremont, S., Wood, K., and Jones, G.N. (2004) Predictors of Emergency Department Patient Satisfaction: Stability over 17 Months. Academic Emergency Medicine, 11, 51-58. http://dx.doi.org/10.1197/j.aem.2003.06.012

[4] Abdullah, M.H. (2005) Study on Outpatients’ Waiting Time in Hospital Universiti Kebangsaan Malaysia (HUKM) Through the Six Sigma Approach 1. The Journal of the Department of Statistics, 1, 39-53.

[5] Plüddemann, A., Thompson, M., Wolstenholme, J., Price, C.P. and Heneghan, C. (2012) Point-of-Care INR Coagulometers for Self-Management of Oral Anticoagulation: Primary Care Diagnostic Technology Update. The British Journal of General Practice, 62, e798-e800. http://dx.doi.org/10.3399/bjgp12x658476

[6] Garcia-Alamino, J.M., Ward, A.M., Alonso-Coello, P., Perera, R., Bankhead, C., Fitzmaurice, D., et al. (2010) SelfMonitoring and Self-Management of Oral Anticoagulation. Cochrane Database of Systematic Reviews, 4, Article ID: CD003839. http://dx.doi.org/10.1002/14651858.cd003839.pub2

[7] British Committee for Standards in Hematology (2011) Guidelines on Oral Anticoagulation (Warfarin). Fourth Edition, Blackwell Publishing Limited.

[8] National Health Service (NHS Columbia) (2014) Guidelines for Anticoagulation.

[9] Garwood, C.L., Baringhaus, S.N. and Laban, K.M. (2008) Quality of Anticoagulation Care in Patients Discharged from a Pharmacist Managed Anticoagulation Clinic after Stabilization of Warfarin Therapy. Pharmacotherapy, 28, 2026. http://dx.doi.org/10.1592/phco.28.1.20

[10] Sharma, P., Scotland, G., Cruickshank, M., Tassie, E., Fraser, C., Burton, C., et al. (2015) The Clinical Effectiveness and cost-Effectiveness of Point-of-Care Tests (CoaguChek System, INRatio2 PT/INR Monitor and ProTime Microcoagulation System) for the Self-Monitoring of the Coagulation Status of People Receiving Long-Term Vitamin K Antagonist Therapy, Compared with Standard UK Practice: Systematic Review and Economic Evaluation. Health Technology Assessment, 19, No. 48. http://dx.doi.org/10.3310/hta19480

[11] NHS Purchasing and Supply Agency (2008) Buyers' Guide: Point of Care Coagulometers for Monitoring Oral Anticoagulation. CEP 07026. Centre for Evidence-based Purchasing, London.

[12] Christensen, T.D. and Larsen, T.B. (2012) Precision and Accuracy of Point-of-Care Testing Coagulometers Used for Self-Testing and Self-Management of Oral Anticoagulation Therapy. Journal of Thrombosis and Haemostasis, 10, 251-260. http://dx.doi.org/10.1111/j.1538-7836.2011.04568.x 
[13] Siebenhofer, A., Rakovac, I., Kleespies, C., et al. (2008) Self-Management of Oral Anticoagulation Reduces Major Outcomes in the Elderly. A Randomized Controlled Trial. Thrombosis and Haemostasis, 100, 1089-1098. http://dx.doi.org/10.1160/th08-06-0361

[14] National Institute for Health and Care Excellence (2006) Atrial Fibrillation. Clinical Guideline CG36. National Institute for Health and Care Excellence, London. http://guidance.nice.org.uk/CG36/NICEGuidance/pdf/English

[15] Gijo, E., Antony, J., Hernandez, J. and Scaria, J. (2013) Reducing Patient Waiting Time in a Pathology Department Using the Six Sigma Methodology. Leadership in Health Services, 26, 2-2. 